\title{
Numerical Study on Combustion and Emissions Performance of DME-methanol Engine
}

\author{
Pengchao Zhang, Cuiping Zhang, Xiaobo Yao, Dongqing Guo \& Shuai Xiao \\ Department of Vehicle Engineering, Taiyuan University of Technology, Taiyuan, 030024, China
}

\begin{abstract}
In this paper, the author uses DME as an additive to methanol diesel, and uses AVL-Fire software to make a simulation analysis to mixed fuel. In the analysis, the mass ratio is fixed by a methanol content of $12 \%$ unchanged. The content of diesel oil are respectively $70 \%, 60 \%, 50 \%$, and $40 \%$, and the rest is DME. Under 2200r/min high load conditions, the author analyzes the combustion process and emission of these four mixed fuels, and compares them with diesel. The results show that: with lowers levels of diesel, the cylinder pressure gradually decreases, the pressure peak where the crank angle is essentially the same, the heat release gradually increases; with the reducing content of diesel, the emissions of NOx increase, while the Soot emissions reduce.
\end{abstract}

Keywords-the engine; DME-methanol; combustion and emission characteristics.

\section{INTRODUCTION}

In the growing shortage of oil resource, the development of clean fuel engine is an imperative trend nowadays. China is a country that rich in coal, poor in oil and less in gas. As a supplement to petroleum resources, based on coal, focusing on the development of alcohol fuels has become one of the main directions of alternative energy cars[1] [3].

DME can be obtained through methanol dehydration or can be synthesized directly in one step synthesis method. To get high purity DME, the requirement to process is stricter, and the production costs is higher. The cetane number in DME is higher than diesel, with good spontaneous combustion characteristics, short ignition delay period, which make the engine has a good cold start performance that is suitable for compression-ignition engines[4] [6]. In the thesis, the author makes a analysis on the ternary mixed fuel of methanol, DME and diesel by using AVL-Fire software, and explores the effects of the combustion and emission characteristics of the blended fuel that adding some methanol, which provide theoretical guidance to the exploration of alcohol fuel.

\section{THE ESTABLISHMENT OF MODEL}

\section{A. The basic parameters of the engine $4100 Q B Z L$}

This model uses 4100QBZL turbocharged and intercooled diesel engine produced by KUNMING YUNNEI POWER CO, LTD. The main technical parameters were shown in Table I. Among them cylinder bore is $100 \mathrm{~mm}$, and piston stroke is $105 \mathrm{~mm}$. The engine is a four-cylinder machine, its compression ratio is 17.5, and computing speed is $2200 \mathrm{r} / \mathrm{min}$. In the calculation, intake stroke is $360^{\circ} \sim 540^{\circ} \mathrm{CA}$, compression stroke is $540^{\circ} \sim 720^{\circ} \mathrm{CA}$, power stroke is $720^{\circ} \sim 900^{\circ} \mathrm{CA}$, exhaust stroke is $900^{\circ} \sim 1080^{\circ} \mathrm{CA}$, and the time of fuel injection is $707^{\circ} \mathrm{CA}\left(13^{\circ} \mathrm{BTDC}\right)$.

TABLE I. PARAMETERS OF 4100 ENGINE

\begin{tabular}{cc}
\hline Parameters & Indicators \\
\hline Cylinder Bore $/ \mathrm{mm}$ & 100 \\
Stroke $/ \mathrm{mm}$ & 105 \\
Compression Ratio & 17.5 \\
Max torque $/ \mathrm{n} /\left(\mathrm{N} \cdot \mathrm{m} /\left(\mathrm{r} \cdot \mathrm{min}^{-1}\right)\right.$ & $245 / 2200$ \\
Rated power $/ \mathrm{n}\left(\mathrm{N} \cdot \mathrm{m} /\left(\mathrm{r} \cdot \mathrm{min}^{-1}\right)\right.$ & $70 / 3200$ \\
Number of Holes x Diameter $(\mathrm{mm})$ & $6 \times 2.4$ \\
Crank Angle at intake valve closed & $48^{\circ} \mathrm{ABDC}$ \\
Crank Angle at exhaust valve open & $65^{\circ} \mathrm{BBDC}$ \\
\hline
\end{tabular}

B. The partition of model grid

Based on the mapping of the combustion chamber and injector's structure parameters, and through the specialized ESE module which in the software FIRE making simplified simulation to diesel engine 4100, the geometric model is a closed space which formed by the top of the piston and the cylinder head and wall after intake and exhaust valves closed. Therefore, do not take into account the exhaust stroke, excluding inlet, intake valves, exhaust and exhaust valves. Simulation process is the mug work processes that during the time from the intake valve close to the exhaust vale open.

Because the simulation process keeps the diesel engine piston reciprocating, so using a moving grid to make a meshing to combustion chamber. The injector of the engine 4100 is a hole nozzle, and there are six spray holes arranged uniformly in the circumferential direction, so that the angle between the nozzle holes is $60^{\circ}$. In order to simplify and make a calculation easily, combustion chamber can be seen here in the center the piston crown symmetrical, and therefore the calculation the combustion chamber when the grid is generated only take one sixth of the combustion chamber, and encrypt the grid at the border department. The combustion model after grid division as following pictures 1 and 2. 


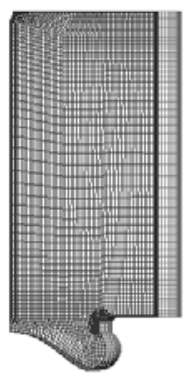

Figure 1. Combustion Chamber Computing Grid at Crank Angle $590^{\circ}$

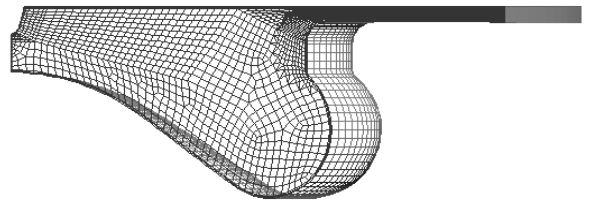

Mesh at position AN_ 720.000

Figure 2. Combustion Chamber Computing Grid at TDC

\section{THE BOUNDARY AND INITIAL CONDITIONS OF MODEL}

In order to reduce computing time, the simulation to combustion process is during the process which from the intake valve closed to the exhaust valve opened. Intake valve closing time is $588^{\circ} \mathrm{CA}\left(48^{\circ} \mathrm{ABDC}\right)$, the exhaust valve opening time is $834.3^{\circ}\left(65.3^{\circ} \mathrm{BBDC}\right)$. Therefore, the calculation start time is $588^{\circ} \mathrm{CA}$, the end time is $834.3^{\circ} \mathrm{CA}$. At the same time, as the trend of $\mathrm{NO}_{\mathrm{x}}$ emissions have basically stable and oxidation rate of Soot also is slow at the moment at the $834^{\circ} \mathrm{CA}$, in order to simplify the calculation, the paper simulation calculation will end at $834^{\circ} \mathrm{CA}$.

In the model calculation, since the bottom of the cylinder head, the top surface of the piston and the cylinder wall surface of the wall are fixed, so the velocity boundary condition is non-slip velocity boundary conditions. The temperature boundary is considered to take constant temperature, and adapting the average temperature of the cylinder head, the cylinder wall and the top surface of the combustion chamber as the corresponding boundary temperature. Set the temperature of BND_ head, BND liner, BND_ piston as $550.15 \mathrm{~K}, 475.15 \mathrm{~K}, 575.15 \overline{\mathrm{K}}$ respectively, the initial temperature is $340.6 \mathrm{~K}$ and the fuel injection temperature is $353 \mathrm{~K}[6]$. Simulate the number of atoms of C,H,O and LHV of fuels, also including TKE and TLS at $2200 \mathrm{r} / \mathrm{min}$.

Turbulence model is $\mathrm{k}-\zeta-\mathrm{f}$ model in the process of engine modeling. Fuel spray model applies WAVE discrete model of FIRE. Evaporation model of fuels utilizes Mufti-component, and combustion model is ECFM-3Z that has well accuracy and convergence. Besides, generation model of $\mathrm{NO}_{\mathrm{x}}$ is Zeldovic, and that of Soot is the common Lund Flamelet Model.

Fix the quality ration of methanol as $12 \%$, add diesel as $70 \%, 60 \%, 50 \%$ and $40 \%$ respectively to the fuel, and the rest add DME. Investigate the combustion and emissions of these four mixed fuels, and compare them with diesel. [7]

\section{RESULTS ANALYSIS}

\section{A. The affection the diesel quantity to combustion characteristics}

Fig 3-7 is contrast curve of combustion characteristics between mixed fuel engine and original engine at $\mathrm{n}=2200 \mathrm{r} / \mathrm{min}$ under $75 \%$ load.

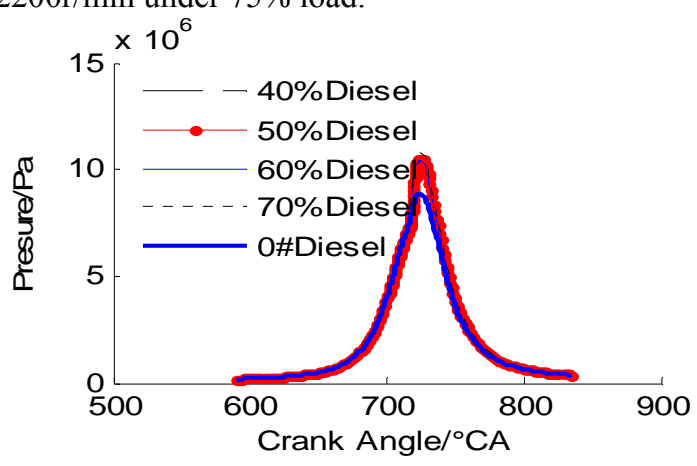

Figure 3. Mean Pressure Comp ration

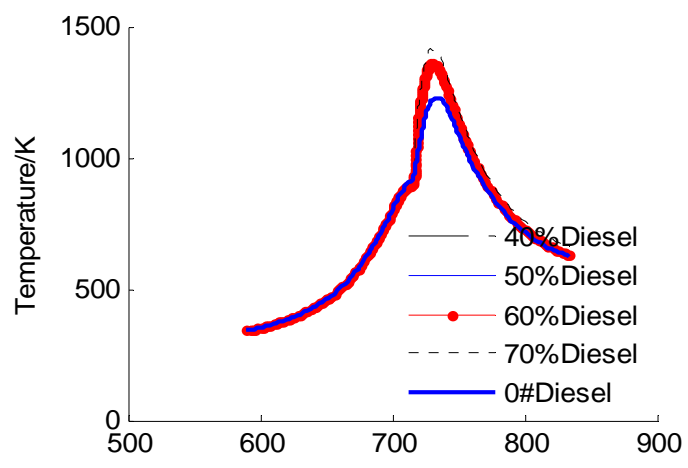

Figure 4. Mean Temperature Comp ration

As can be seen from Fig.3, with the decrease of the content of diesel fuel, the cylinder pressure is gradually deceased, the pressure peak crank angle is substantially constant, the ignition delay period is slightly shorter, and the maximum in-cylinder pressure of the mixed fuel is higher than that of diesel. This is due to the diesel content is becoming lower, and the content of DME is becoming higher, and the DME will produce strong pressure boiling when the mixed fuel injected into the cylinder. At high speed and high load conditions, cylinder temperature is higher, which makes the DME evaporate quickly, and mixed fuel atomization performance also will be improved. Integrated reasons lead the result that the pressure of in-cylinder of the mixed fuel is becoming lower with a reducing of the diesel's contents.

Figure 4 is a contrast curve that the cylinder temperature 
between hybrid fuel engine and diesel. From the picture, cylinder temperature is gradually reduced with the reducing of the diesel content, but the temperature of mixed fuel engine should be higher than that of the diesel. After the mixed fuel injected into the cylinder, the cylinder temperature has dropped, this is because the latent heat of vaporization value of mixed fuel is higher than that of diesel fuel. With the diesel content reducing gradually, latent heat of vaporization of the fuel mixture increases, which leads to the cylinder temperature decreases. Cylinder maximum temperature of the mixed fuel are higher than that of diesel, which shows the atomization performance of mixed fuel is good, it can burn more fully , and its thermal efficiency is higher than diesel.

Figure 5 is heat release rate of mixed fuel engine and that of diesel contrast curve. As can be seen from the figure the heat release rate of the mixed fuel is higher than that of diesel and with the decrease of the content of diesel fuel has a tendency to increase. DME improves the atomization performance the hybrid fuel, the higher the content, the better fuel atomization performance, which makes up the shortcomings of poor atomization of methanol. Meanwhile, due to the fire performance of DME is good, it prone to severe burning, adding methanol can also limit their occurrence, the two form can make complementary advantages. Compared with diesel fuel, the burning of mixed fuel can burn fully, the fuel efficiency is higher.

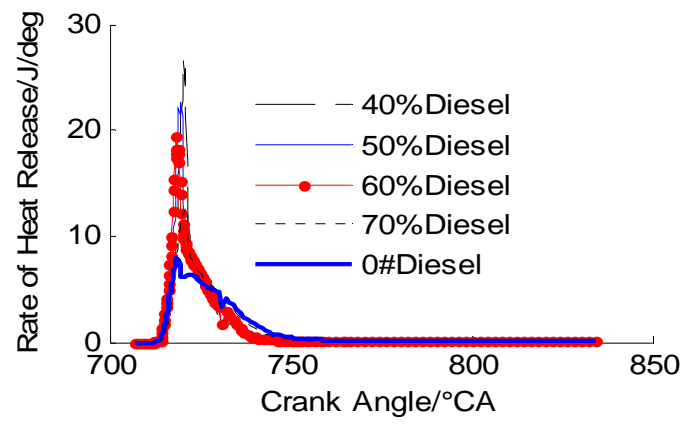

Figure 5. The Rate of Heat Release Comp ration

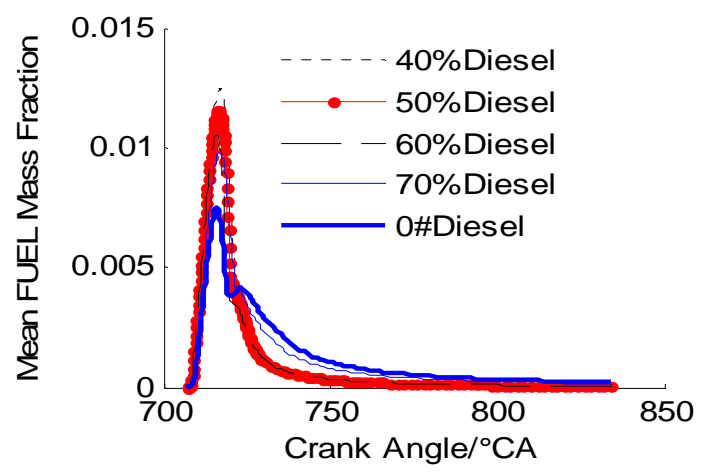

Figure 6. Fuel Mass Fraction Comp ration

Figure 6 shows the contrast curve between the mass fraction of the hybrid fuel engine and the diesel engine. As can be seen from the figure the injection speed of the fuel mixture is higher than diesel fuel, the less content of the diesel fuel, the higher the ejection speed; but when the injection ends, the mass fraction of the mixed fuel is lower than that of the diesel fuel, and its value will be lower as the content of DME increasing. This explains the mixed fuel atomization performance is much higher than diesel, the lower the content of diesel, the higher the content of DME is, the better the atomization performance will be, the fuel can be burned more fully, and fuel efficiency is becoming higher.

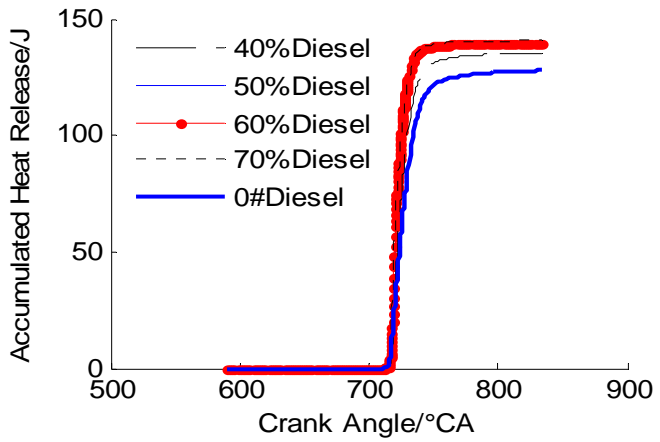

Figure 7. Accumulated Heat Release Comp ration

Figure 7 is the contrast curve of accumulated heat release between mixed fuel engine and diesel. According to the picture, the cumulative heat release of hybrid fuel engine is higher than that of the diesel. And with diesel fuel content decreases, the accumulated heat release of mixed fuel engine will be reduced, but not very different. This shows that the mixed fuel can be burned more fully than diesel, and its thermal efficiency is higher.

\section{B. Diesel content Impact on the emission characteristics}

Figures 8 and 9 are respectively comparing curve of NOx and Soot emissions between mixed fuel engine and diesel.

As can be seen from Figure 8, the NOx emissions of the mixed fuel engine is higher than the diesel engine, the lower the content of diesel fuel, the higher the NOx emissions. The generations of NOx are mainly two ways: First, the high temperature combustion zone pathways that have been generated NOx, called thermal NOx; second is the instantaneous way, NOx is generated in the flame zone, called prompt NOx. Factors which affecting NOx generated include temperature, oxygen concentration and gas residence time at high temperature[8].Mixed fuel contains oxygen, the oxygen concentration is higher than that of diesel, and the maximum cylinder temperature of the mixed fuel is greater than the diesel fuel, so its burning rate is also faster, which makes the combustion zone has remained a great deal of unburned air in burned area, and there is still a lot of unburned air, which provides NOx formation with oxygen-rich conditions of high temperature and the residence time in high temperature environment is longer . The higher the content of DME, the faster the burn rate, the higher the oxygen concentration, which leads to higher NOx emissions. 


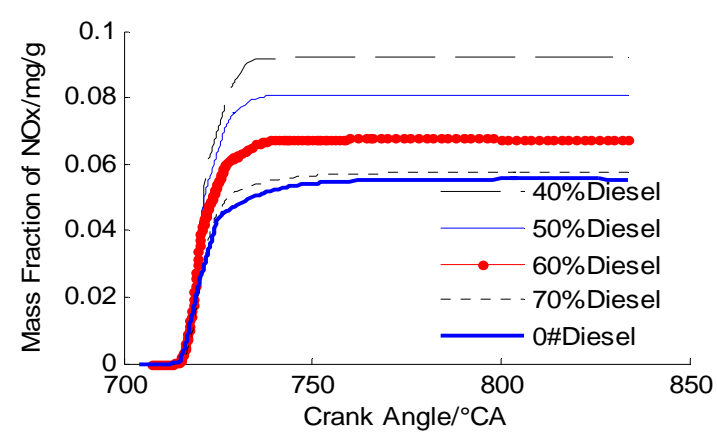

Figure 8. NOx Mass Fraction

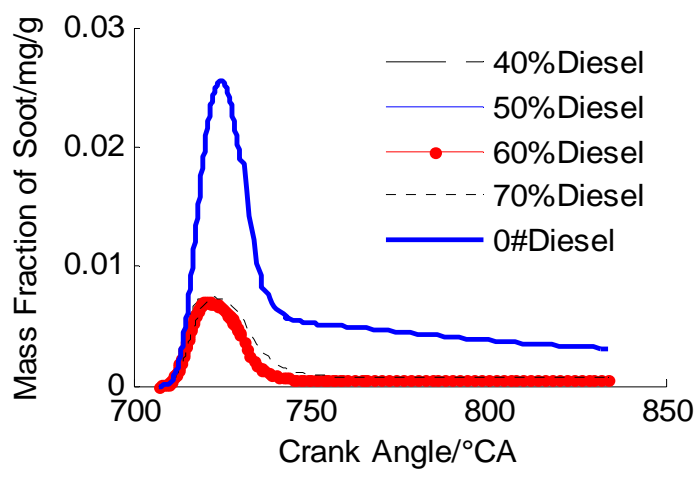

Figure 9. Soot Mass Fraction

Figure 9 is a comparing curve of Soot emissions between mixed fuel engine and diesel fuel engine. As can be seen from the figure, the Soot emissions of blended fuel is much lower than that of diesel fuel, basically reaching the non-smoking emission, and with reducing diesel content, the Soot emissions is lowering. The condition of Soot formation need high temperature and lack oxygen, fuel mixture oxygenates, and its oxygen concentration is higher than that of diesel. The lower of the content of diesel fuel, the higher the oxygen concentration of the mixed fuel, the more chance of the fuel in contact with oxygen, and the higher of the content of DME, the better the atomization performance of the fuel, more uniform distribution in the cylinder, reducing the uneven combustion, making combustion more fully and higher fuel efficiency, and thus gets lower Soot emissions.

\section{V.CONCLUSION}

i) By using AVL-FIRE, mixed fuels of methanol, DME and diesel were simulated and analyzed to explore the impact of the diesel content on combustion and emission characteristics of the mixed fuels.

ii) Compared with diesel, mixed fuel combustion was more fully, and it has higher fuel efficiency, and its efficiency has improved.

iii) With the decrease of diesel content in the fuel blends ,the emission of NOx increases, but the emission of Soot decreases, so it reaches smoke-free emissions basically.

\section{REFERENCES}

[1] Chen Wei-Guo., Trends in alternative fuel development for vehicle use. Sustainable Development, 2, pp.31-42, 2007.

[2] Chen Mao-Tao., DME-The diesel engine alternative fuel for the $21^{\text {st }}$ century. Applied Chemical Industry, 8, pp. 7-9, 2001.

[3] Chen Yong-Tian., Study on Unconventional Pollutant Emission Performance of DME-methanol Engine. Vehicle Engine, 4, pp. 68-73, 2012.

[4] Li Xiao-Fen. Simulation Study on Combustion and Emission Process of High Proportion OF DME-Diesel Mixed Fuel. Taiyuan: Taiyuan University of technology, 2010.

[5] Wu Jun-Hua, Huang Zhen \& Qiao Xin-Qi. Study on Combustion and Emissions Characteristics of Turboc-hanged Engine Fuelled with Dimethyl Ether. Int J Automotive Technology, 2006.7 .

[6] Su Han Park \& Chang Sik Lee. Combustion performance and emission reduction characteristics of automotive DME engine system. Progress in Energy and Combustion Science, 39, pp. 147-168, 2013.

[7] Cao Jie. Study on Combustion and Emission of Impure DME-Diesel Blended Fuel. Taiyuan: Taiyuan University of technology, 2011.

[8] Zhang Cui-Ping \& Wang Tie. Emissions and Control of Internal Combustion Engine. Beijing: China Machine Press, 2013 